\title{
MÉTODOS DE DETERMINAÇÃO DE UMIDADE NOS SOLOS DE CERRADO
}

Andréia da Cruz Quintino ${ }^{1}$; Patrícia de Jesus Andrade ${ }^{1}$; Tonny José da Silva ${ }^{2}$; Maria Aparecida Caneppele ${ }^{2}$; Joadil Gonçalves de Abreu $^{2}$

1 Doutorandas em Agricultura Tropical da Universidade Federal de Mato Grosso (andreiaquintino@yahoo.com.br) Cuiabá-Brasil

2 Professores Doutores da Universidade Federal de Mato Grosso, Cuiabá-Brasil

Recebido em: 08/09/2015 - Aprovado em: 14/11/2015 - Publicado em: 01/12/2015 DOI: http://dx.doi.org/10.18677/Enciclopedia_Biosfera_2015_193

\section{RESUMO}

Objetivou-se neste trabalho determinar a umidade do solo pelo método da estufa, forno de microondas e infravermelho, em cinco perfis de solos do Cerrado. $O$ experimento foi realizado com cinco perfis de solos, existentes na Fazenda Experimental da UFMT, no município de Santo Antônio de Leverger, MT, (15\%4'5' Sul, e 5604' Oeste), na microrregião da Baixada Cuiabana. O delineamento experimental utilizado foi inteiramente casualizado, em esquema fatorial $5 \times 2 \times 3$, sendo cinco perfis de solos, duas profundidades $(0-0,20$ e $0,20-0,40 \mathrm{~m})$ e três métodos de determinação de umidade, com quatro repetições. Os perfis dos solos foram classificados como: Plintossolo Pétrico êutrico, Plintossolo Pétrico típico, Planossolo Nátrico, Latossolo Amarelo e Neossolo Quartzarênico, as amostras destes solos foram coletadas no mês de junho de 2012. A umidade do solo foi determinada pelos métodos da estufa, forno de micro-ondas doméstico e infravermelho, em duplicata para cada repetição. Os resultados de umidade do solo não diferiram estatisticamente $(P>0,05)$, quando se utilizou estufa a $105^{\circ} \mathrm{C}$, microondas e infravermelho, ou seja, apresentaram resultados semelhantes. $O$ uso de micro-ondas pode ser uma alternativa viável nas condições da propriedade rural, enquanto o infravermelho pode ser utilizado para calibração rápida de métodos indiretos.

PALAVRAS-CHAVE: calibração, infravermelho, micro-ondas

\section{METHODS OF MOISTURE DETERMINATION IN SOIL OF CERRADO}

\begin{abstract}
The objective of this work was to determine the soil moisture by the oven method, microwave and infrared, in five soil profiles of the Cerrado. The experiment was conducted with five soil profiles, existing at the UFMT Experimental Farm, in Santo Antônio de Leverger, MT, (1547'5" South and 5604 'West) in the Baixada Cuiabana micro region. The experimental design was completely randomized in factorial scheme $5 \times 2 \times 3$, five soil profiles, two depths $(0-0,20$ and $0,20-0,40 \mathrm{~m})$ and three moisture determination methods, with four replications. The soil profile were
\end{abstract}


classified as Petroferric Eutrophi Eutric, Petroferric Eutrophi Typic, Natrustalfs, Typic Hapludoxand Typic Quartzipisamment, these soil samples were collected in June 2012. Soil moisture was determined by the methods of the oven, microwave oven and infrared, in duplicate for each repetition. The results of soil moisture did not differ $(P>0,05)$, when using the oven at $1^{\circ} 5^{\circ}$, micro wave and infrared, than showed similar results. The use of micro waves can beaviable alternative inconditions of rural property, while the infrared can be used forrapid calibration of indirect methods.

KEYWORDS:calibration, infrared, microwave

\section{INTRODUÇÃO}

A importância da umidade no solo em sistemas agrícolas foi reconhecida há bastante tempo. O crescimento das plantas e a produtividade das culturas talvez estejam mais proximamente relacionados com a umidade no solo que qualquer outro elemento meteorológico isolado, inclusive a chuva (BAIER \& ROBERTSON, 1968). A busca da viabilidade econômica do processo de produção vegetal tem levado os produtores à adoção de técnicas de agricultura de precisão (GONÇALVES et al., 2010). Contudo, o conhecimento do regime de umidade no solo reveste-se de importância no fornecimento de informações destinadas a resolver problemas, como manejo de irrigação, escolha da época de semeadura, determinação do consumo de água pelas plantas, estudo dos processos de transferência no sistema solo-plantaatmosfera e planejamento dos sistemas de drenagem (ARAÚJO, et al., 2001).

Neste sentido, o preparo do solo e o tráfego de máquinas em condições de umidade inadequada (consistência no estado plástico) provocam deformações plásticas (MAZURANA et al., 2011) e podem formar zonas de compactação ao longo do perfil, reduzindo a qualidade física, determinada em razão da redução da macroporosidade. Isso dificulta as trocas gasosas do solo com a atmosfera externa e provoca a redução do sistema radicular (ORTIGARA et al., 2014).

A umidade a base de peso é a mais fácil de ser medida, pois envolve apenas medidas de peso, e a estrutura do solo pode ser destruída. Por isso, qualquer instrumento pode ser utilizado para retirar a amostra de solo, que deve ter, no mínimo, uma massa entre 10 a100 g de solo (SCARAMUZZA et al., 2003). O estudo de métodos alternativos para determinação de umidade em diferentes classes de solos no Cerrado é muito válido para gerar conhecimentos básicos sobre as técnicas de determinação do teor de água no solo. Diversos são os métodos de determinação da umidade do solo (FREITAS et al., 2012). Assim sendo, o método do forno microondas, é mais acessível na realidade das propriedades agrícolas, podendo auxiliar no monitoramento do solo e principalmente na preservação das características químicas, físicas e biológicas do solo, que por sua vez são dependentes do conteúdo de água no solo (MIRANDA et al., 2012).

A presente tecnologia é um método alternativo ao método convencional de secagem de solo e de planta. O método convencional utiliza a estufa de secagem como equipamento e demanda de 12 até 72 horas para completar o teste. Já o método alternativo utiliza o forno de micro-ondas doméstico como equipamento e demanda 10 ou 15 minutos para secar solo ou planta, respectivamente. O fornecimento de dados relacionados ao teor de massa seca ou umidade deve ser rápido e confiável, pois a partir dessas informações algumas ações são tomadas. Como exemplo, esta informação é importante para verificar se há ou não 
necessidade de continuar adicionando água de irrigação em determinada cultura (SOUZA et al., 2002).

A determinação por meio de infravermelho tem sido promissora na determinação de umidade, pois ocorrem agilidade e precisão nas análises laboratoriais. Desta forma, o objetivo neste trabalho foi determinar a umidade do solo pelo método da estufa, forno de micro-ondas e infravermelho, em cinco perfis de solos do Cerrado.

\section{MATERIAL E MÉTODOS}

O experimento foi realizado no mês junho de 2012, utilizando-se cinco perfis de solos, existentes na Fazenda Experimental da UFMT, no município de Santo Antônio de Leverger, MT, próximo das coordenadas de 15047'5" Sul, e 5604' Oeste, e altitude de $140 \mathrm{~m}$, na microrregião da Baixada Cuiabana. O clima da região é do tipo Aw (Clima de Cerrado), segundo classificação de Köppen. Os perfis de solos da área experimental foram classificados de acordo com EMBRAPA (2006), conforme Tabela 1.

TABELA 1 Análise física e química dos perfis dos solos

\begin{tabular}{|c|c|c|c|c|c|c|c|}
\hline C & & Profundidade & Areia & Silte & Argila & $\mathrm{pH}$ & *V \\
\hline & & $\mathbf{c m}$ & & $\%$ & & $\mathrm{KCl}$ & $\%$ \\
\hline Plint & A & $00-60$ & 73,3 & 10,0 & 16,7 & 4,9 & 62 \\
\hline Quartzarênico & $A$ & 7 & 87,3 & 3,4 & 9,3 & 4,2 & 50 \\
\hline Plintossolo Pétrico típico & Acp & $\zeta$ & 77,3 & 8,3 & 14,4 & 5,0 & 45 \\
\hline Latossolo Amarelo & $\mathrm{B}$ & $12-44$ & 76,6 & 6,7 & 16,7 & 4,2 & 5 \\
\hline Planassolo Nátrico & Btg & $14-70$ & 29,9 & 23,4 & 46,7 & 6,0 & 94 \\
\hline
\end{tabular}

Fonte: Adaptado de EMBRAPA (2006). *V: Saturação por bases.

As amostras de solos coletadas nas profundidades de 0-0,20 m e 0,20-0,40 $\mathrm{m}$, com quatro repetições, foram homogeneizadas, acondicionadas em sacos plásticos e levadas ao Laboratório para as análises. O experimento foi montado no delineamento inteiramente casualizado, em esquema fatorial $5 \times 2 \times 3$, sendo cinco perfis de solos, duas profundidades $(0-0,20$ e $0,20-0,40 \mathrm{~m})$ e três métodos de determinação de umidade, com quatro repetições. Foi adotado o teste de Tukey a $5 \%$, para comparação das médias, utilizando-se o software Sisvar.

A umidade do solo foi determinada pelos métodos de estufa de secagem, forno de micro-ondas doméstico e balança de infravermelho, em duplicata para cada repetição.

\section{Determinação de umidade pelo método da estufa de secagem}

$O$ processo de secagem pelo em estufa de secagem a $105^{\circ} \mathrm{C}$ por 48 horas, foi segundo EMBRAPA (1997). Para a execução deste método tomou-se a massa de solo úmido $\left(m_{u}\right)$, em seguida colocou-se em estufa de secagem a $105-110^{\circ} \mathrm{C}$ até massa constante, aproximadamente 24 horas. A massa constante foi registrada como a massa de solo seco $\left(m_{s}\right)$ e com a equação 1 , calculou-se a umidade atual à base de peso $(U)$. 


$$
U(\%)=\left(\frac{m_{u}-m_{s}}{m_{s}}\right) \times 100
$$

Equação 1

\section{Determinação de umidade utilizando forno micro-ondas}

As determinações em forno micro-ondas foram efetuadas em sete minutos a 640 watts e três minutos a 358 watts. Estes valores se referem a $90 \%$ e $50 \%$, respectivamente, da potência do forno de micro-ondas utilizado para desenvolvimento deste método. As amostras, de $40 \mathrm{~g}$, de solos foram acondicionadas em cadinhos de porcelana e colados no prato do micro-ondas sob a potência e tempo descritos acima, após o processo foram pesadas, e com os valores de massa de solo úmido e seco calculou-se a umidade conforme equação 1.

Antes de iniciar a determinação de umidade foi realizada a calibração do forno de micro-ondas para verificar a reprodutibilidade de aquecimento do forno e também conhecer o valor da temperatura e da potência real de trabalho, de acordo com a metodologia descrita por SOUZA et al. (2002). Primeiramente equilibrou-se 5 litros de água na temperatura ambiente $\left(23 \pm 2^{\circ} \mathrm{C}\right)$. Da água exposta a temperatura ambiente, retirou-se $1 \mathrm{~kg}$ e a depositou em um béquer de propetileno, registrando a temperatura inicial. Em seguida o béquer coberto, por água, foi colocado para aquecer no prato do forno de micro-ondas durante dois minutos na potência máxima indicada (100\%), ao final do processo retirou-se o béquer do forno micro-ondas, e com o auxílio de um bastão de vidro agitou-se a água vigorosamente por 30 segundos, e registrou-se a temperatura final, com termômetro de precisão de \pm $0,05^{\circ} \mathrm{C}$. Esse mesmo procedimento foi repetido por mais duas vezes, na potência de $100 \%$ e três vezes para as potências de $80,60,40$ e $20 \%$, com a finalidade de obter a média de temperatura ( $\mathrm{T}$ ) e calcular a potência da unidade de micro-ondas, utilizando a equação 2.

$$
P=34,86 \times T
$$

Equação 2

Em que:

$\mathrm{P}=$ potência aparente absorvida pela amostra em watts $\left(\mathrm{W} \mathrm{J}\right.$ segundos $\left.{ }^{-1}\right)$.

$\mathrm{T}=$ temperatura final menos temperatura inicial $\left({ }^{\circ} \mathrm{C}\right)$.

\section{Determinação de umidade por balança de infravermelho}

Para obter a umidade de um solo utilizando a balança de infravermelho OHAUS ${ }^{\circledR}$ modelo MB 200 foi necessário, primeiramente, a determinação de curvas de secagem para conhecer as características dos solos. A elaboração da curva consiste em secar uma amostra, a uma determinada temperatura, e anotar a porcentagem de umidade perdida, desta amostra, a cada um minuto, até atingir valor constante (foi considerado valor constante cinco registros iguais). Os valores obtidos foram plotados em gráficos, e considerou que o tempo necessário para secar o material, na temperatura estudada, é quando registrou-se a mesma porcentagem de umidade durante cinco minutos. As curvas foram feitas nas temperaturas de 105 , 130, 150, 185 e $200^{\circ} \mathrm{C}$, para maior eficiência do teste e selecionar o tempo e a temperatura de secagem das amostras de solo. É importante certificar que o aquecimento programado não altera as características físicas da amostra (como a cor). As curvas de calibração foram realizadas para as classes de solos Plintossolo Pétrico êutrico, Latossolo Amarelo e Planassolo Nátrico. 
Escolhida a temperatura e o tempo de secagem (185으 e cinco minutos), procedeu-se a determinação de umidade do solo seguindo os seguintes passos: selecionou-se o tempo e a temperatura de secagem, na balança; posicionou-se um recipiente de alumínio sobre a plataforma da balança e pressionou o tare; foi espalhada uma camada uniforme de solo (aproximadamente $10 \mathrm{~g}$ ), sobre 0 recipiente de alumínio e iniciou-se o teste. Um sinal sonoro foi emitido indicando o final do teste, a porcentagem de umidade é registrada no display da balança.

\section{RESULTADOS E DISCUSSÃO}

ÁVILA et al., (2011) comentam que a umidade do solo desempenha papel importante nos processos hidrológicos de superfície e transporte de sedimentos devido à relevante participação na separação da precipitação em infiltração e escoamento superficial. Além disso, exerce influência na interação solo-atmosfera, especialmente na evapotranspiração e na interferência dos processos vinculados à erosão hídrica, sendo, de utilidade para extensa faixa de aplicações visando à conservação do solo e da água, portanto, o conhecimento de técnicas alternativas e rápidas de determinação de umidade podem auxiliar em decisões de algumas operações agrícolas, como no manejo de irrigação.

Os valores de umidade do solo, de modo geral, não diferiram estatisticamente $(P>0,05)$, quando utilizou-se estufa de secagem a $105^{\circ} \mathrm{C}$, forno micro-ondas e infravermelho (Tabela 2). Assim, pode-se inferir que na determinação da umidade os três métodos utilizados são eficientes. Então a escolha do método será dependente da acessibilidade e praticidade. Embora, não houve diferença estatísticas entre os métodos, observou-se que o forno micro-ondas apresentou valores de umidade acima dos demais, superestimando o resultado.

Observa que, na camada de 0,20-0,40, o teor de umidade do Plintossolo Pétrico típico, no forno micro-ondas, diferiu estatisticamente dos outros métodos, isso pode estar relacionado com o teor de ferro existente neste solo, que na presença das ondas causa uma dispersão da água e agitação das moléculas, como observado por CREMOM, et al. (2014). TAVARES et al. (2008) discutem que em análise de solo com elevado teor de ferro, a energia das micro-ondas estabelecem diferentes gradientes térmicos dentro do sistema a ser aquecido pela radiação.

Não foi possível determinar a umidade do Planassolo Nátrico no método infravermelho, devido à alta pegajosidade e plasticidade deste solo, que impossibilita a homogeneização adequada das amostras, o que interfere no processo de secagem.

As determinações de umidade na profundidade de 0,20 a $0,40 \mathrm{~m}$ apresentaram menor coeficiente de variação do que 0 a $0,20 \mathrm{~m}$, provavelmente devido à maior uniformidade na distribuição de água com a profundidade. A reprodutibilidade dos resultados, quando da utilização dos métodos de micro-ondas e infravermelho, valida a utilização em substituição à estufa. Entretanto, as considerações acima devem ser ponderadas. Se o propósito desta determinação for à obtenção de valores absolutos de conteúdo de água do solo, deve-se optar pela metodologia da estufa, por ser um método consagrado. Mas se o propósito for voltado às variações do conteúdo de água ou a avaliação para uma tomada de decisão rápida os valores das outras metodologias são válidos. 
TABELA 2 Umidade (\%) dos solos obtido em três métodos de determinação, nas profundidades de 0-0,20 e 0,20-0,40 m

\begin{tabular}{|c|c|c|c|c|c|}
\hline \multirow{2}{*}{ Classe } & \multirow{2}{*}{ Profundidade } & \multicolumn{3}{|c|}{ Métodos } & \multirow{2}{*}{${ }^{*}$ C.V. } \\
\hline & & Estufa & Micro-ondas & Infravermelho & \\
\hline & $\mathrm{m}$ & & $(\%)$ & & (\%) \\
\hline Plintossolo & $0-0,20$ & $10,74 \mathrm{~A}$ & $10,97 \mathrm{~A}$ & $9,68 \mathrm{~A}$ & 21,88 \\
\hline Pétrico êutrico & $0,20-0,40$ & $8,88 \mathrm{~A}$ & $8,84 \mathrm{~A}$ & $8,46 \mathrm{~A}$ & 18,70 \\
\hline Neossolo & $0-0,20$ & $8,04 \mathrm{~A}$ & $8,27 \mathrm{~A}$ & $7,87 \mathrm{~A}$ & 15,53 \\
\hline Quartzarênico & $0,20-0,40$ & $8,82 \mathrm{~A}$ & $8,94 \mathrm{~A}$ & $8,38 \mathrm{~A}$ & 8,02 \\
\hline Plintossolo & $0-0,20$ & $6,82 \mathrm{~A}$ & $7,10 \mathrm{~A}$ & $6,63 \mathrm{~A}$ & 6,49 \\
\hline Pétrico típico & $0,20-0,40$ & $6,18 \mathrm{~A}$ & $7,39 \mathrm{~B}$ & $6,26 \mathrm{~A}$ & 6,30 \\
\hline Latossolo & $0-0,20$ & $7,56 \mathrm{~A}$ & $8,50 \mathrm{~A}$ & $8,03 \mathrm{~A}$ & 18,62 \\
\hline Amarelo & $0,20-0,40$ & $7,73 \mathrm{~A}$ & $8,03 \mathrm{~A}$ & $7,42 \mathrm{~A}$ & 10,11 \\
\hline Planassolo & $0-0,20$ & $14,29 \mathrm{~A}$ & $16,13 \mathrm{~A}$ & - & 14,06 \\
\hline Nátrico & $0,20-0,40$ & $16,22 \mathrm{~A}$ & $17,84 \mathrm{~A}$ & - & 15,89 \\
\hline
\end{tabular}

Médias seguidas por letras iguais, na mesma linha, não diferem estatisticamente entre si, pelo teste de Tukey $(P>0,05) .{ }^{*} \mathrm{C} . V .:$ coeficiente de variação.

Com relação ao método do forno de micro-ondas doméstico, foi observado que houve crescimento linear com o aumento da potência, com incremento de 6,972 W, a cada unidade de potência (Figura 1). Essa equação deve ser avaliada periodicamente, caso mudança significativa seja detectada $( \pm 10 \mathrm{~W})$, a calibração deve ser refeita.

TAVARES et al. (2008), constataram que é possível verificar a aplicabilidade da técnica de micro-ondas na determinação da umidade do solo, com a redução do tempo necessário para o trabalho, pois nos solos analisados, o tempo médio para a completa depleção da umidade foi de 240 segundos. No presente trabalho, o tempo para secagem das amostras de solos foram de 600 segundos, em função da potência do forno de micro-ondas, ou seja, para a utilização deste método deve se conhecer sobre a potência do mesmo. A potência é variável entre os fornos microondas, portanto é necessário a calibração dos aparelhos antes de realizar a determinação de umidade. 


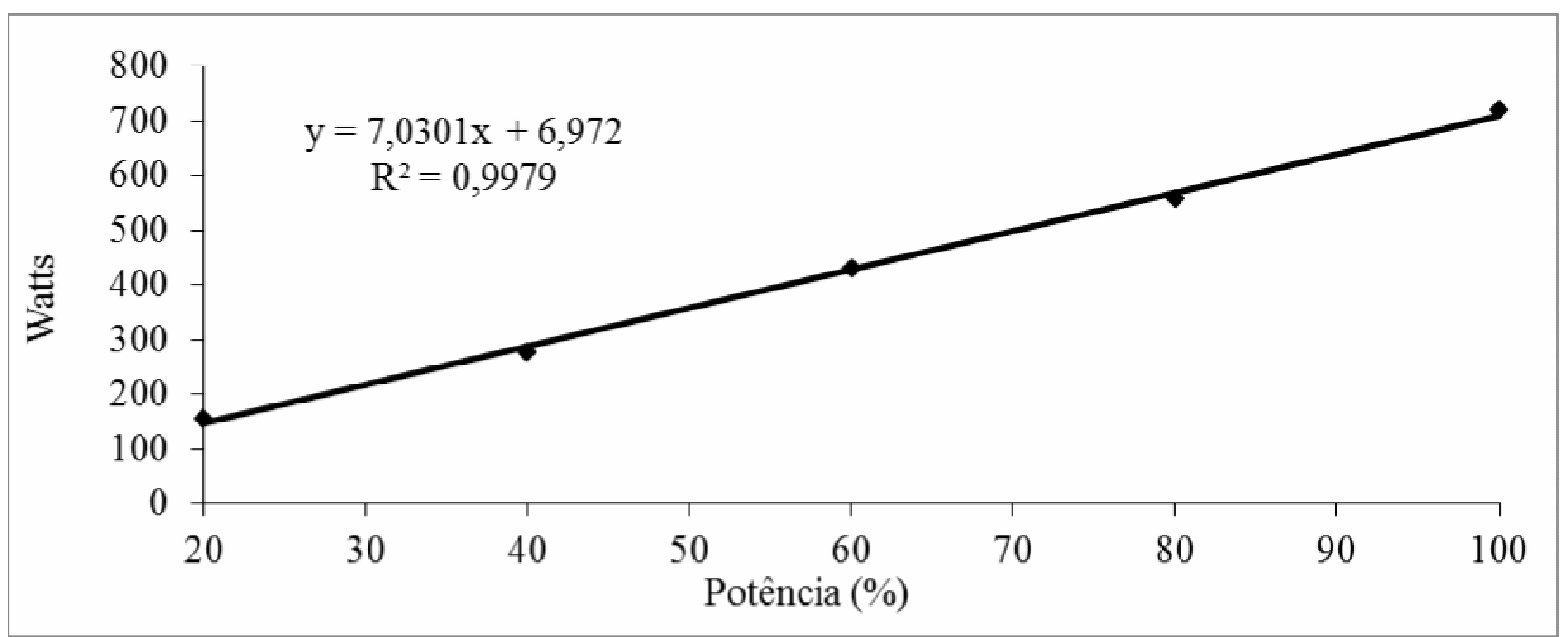

FIGURA 1 Calibração da potência do forno de micro-ondas doméstico

Esse método tem vantagem na execução, pois não exige aparelhagem sofisticada, tem baixo custo relativo e a rapidez, podendo ser indicado para a determinação de umidade, mesmo em locais menos equipados e favorecidos, como na propriedade agrícola. Não houve a necessidade de calibração do forno de microondas para as diferentes classes de solo, ou seja, utilizou-se a mesma rampa de aquecimento para as diferentes classes. TAVARES et al. (2008) afirmam que o processo de secagem no forno de micro-ondas tem maior efeito sobre solos argilosos em relação àqueles arenosos, este fato pode ser explicado pelo microondas agir de forma mais eficiente em solos com maior teor de argila, pois as partículas de argila retêm em suas propriedades a água disponível para a cultura.

Observou-se que o método da estufa é o mais viável quando a quantidade de amostras de solo é elevada, mas demandam um tempo maior em comparação aos demais métodos. Os dados mostram que o método do forno micro-ondas, proposto, pode ser usado para a determinação da umidade atual em amostras de solo, pois os resultados não diferem do método gravimétrico padrão de secagem em estufa. É um método simples e rápido que possibilita a determinação de umidade na propriedade agrícola.

A determinação da umidade do solo em campo pode ser realizada localmente por meio de métodos não destrutivos e indiretos, que garantem um mínimo de perturbação no ambiente para que a medição não seja afetada pelo procedimento adotado. O mais usual é o refletômetro com domínio de frequência (FDR), além do refletômetro com domínio temporal (TDR) e a sonda de nêutrons. Entretanto, estes métodos devem ser calibrados com valores obtidos em métodos diretos. O Microondas mostra-se uma alternativa viável para a conferência dos valores de umidade obtido por métodos indiretos.

Embora vários trabalhos mostrem que a secagem de solos em forno de microondas pode ser empregada com sucesso, com relação a outras análises os resultados são diferentes (TAVARES et al., 2008), por exemplo, TOMÉ \& DECHEN (1995) mostraram que a irradiação por micro-ondas pode acarretar mudanças nos resultados de análises químicas e mineralógicas. Outra observação a ser é feita é quanto ao tamanho das amostras, como discutido por CREMOM et al. (2014) ao observarem diferenças nas determinações de umidade por micro-ondas em amostras de diferentes massas, no qual concluíram que amostras de $40 \mathrm{~g}$ de solo 
apresentaram melhor efeito no processo de secagem pelo método micro-ondas em relação as de 20 e $60 \mathrm{~g}$.

A metodologia utilizando balança de infravermelho é rápida e prática, por ser também um método direto, este possibilita a aferição de aparelhos que medem a umidade de solos de forma indireta. Além disso, poderia ser mais vantajoso para as análises de controle de qualidade de um laboratório mais equipado, onde o número de amostras geralmente é elevado.

O comportamento do tempo de secagem na balança de infravermelho, em função de diferentes massas úmidas de material, é mostrado na Figura 2. Obteve-se uma correlação de 0,95 entre a massa de solo a ser secado e o tempo de secagem. Quanto maior a temperatura menor o tempo de secagem, entretanto deve-se observar que as temperaturas mais elevadas não queimem outros constituintes das amostras, como matéria orgânica, alterando os resultados. Diante disso, pode ser adotada a temperatura de $200^{\circ} \mathrm{C}$ para determinação da umidade dos diferentes solos analisados neste experimento, com tempo médio de 180 segundos. Porém, para maior segurança de que estava havendo somente perda de água, foi adotada a temperatura de $185^{\circ} \mathrm{C}$ por cinco minutos para a determinação de umidade dos diferentes perfis de solo. O tempo de cinco minutos foi escolhido pois a partir deste minuto não houve alteração na umidade do solo.

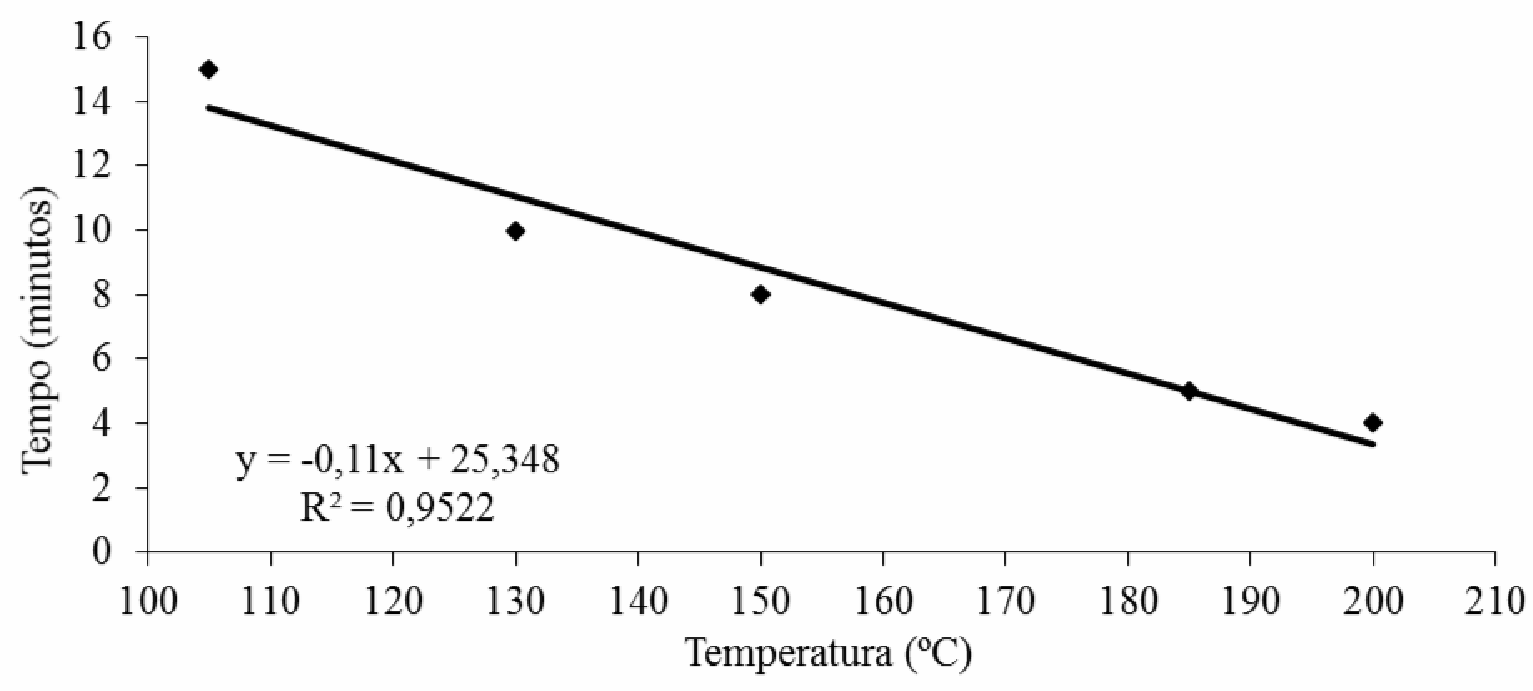

FIGURA 2 Relação entre a temperatura e o tempo de secagem das amostras de solos

Para o Planassolo Nátrico, devido às características físicas dessa classe de solo, o qual dificultou a homogeneização e uniformidade da amostra, o tempo estimado para a secagem foi de 25 minutos. Pela dificuldade de se trabalhar com este solo, foram realizadas somente as curvas de secagem para a calibração (Figura 3). 


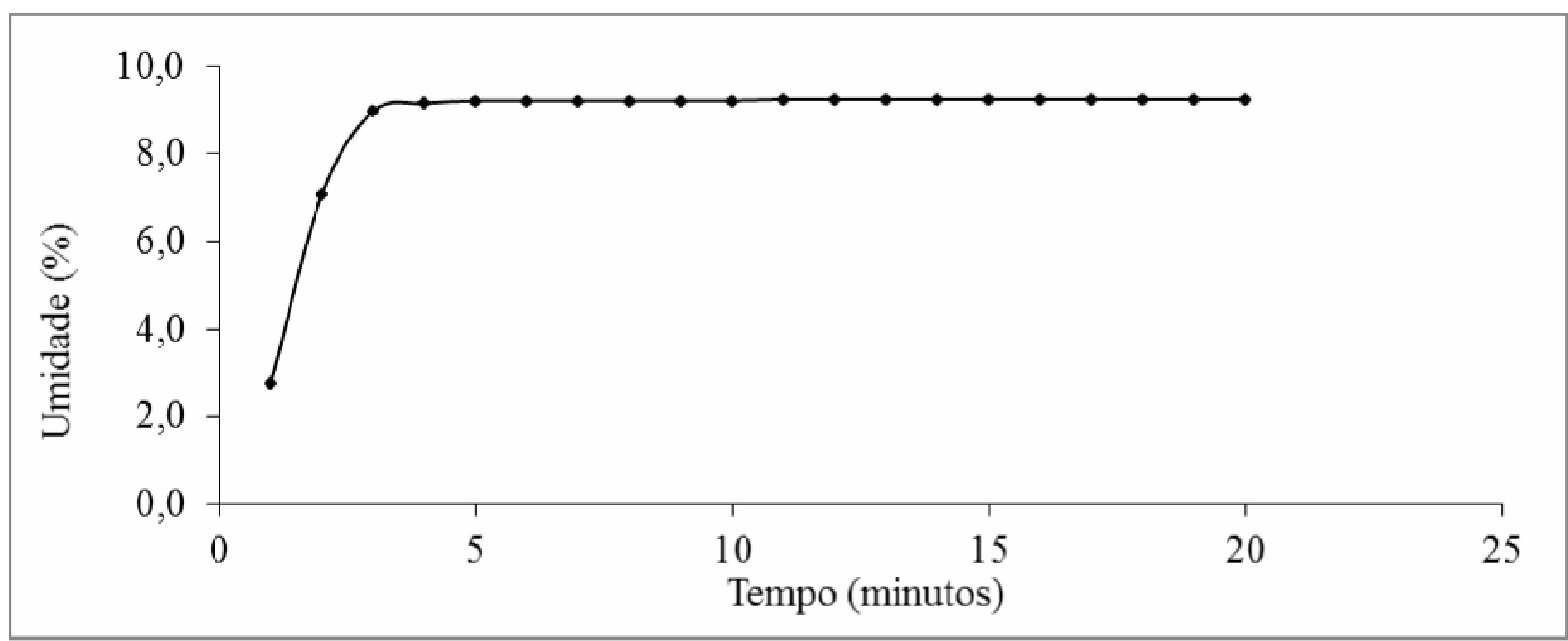

FIGURA 3 Curva de secagem da classe de solo Planassolo Nátrico, profundidade de $0,20-0,40 \mathrm{~m}$

A velocidade de secagem aumenta rapidamente no início da secagem, em seguida, o processo ocorre lentamente até estabilizar. Se continuar o processo de secagem, pode ocorrer um novo aumento de umidade, devido à perda de outros constituintes. A velocidade de secagem, no início do processo, independe da umidade inicial da amostra (Figuras 4 e 5). Assim, a partir dos 240 segundos não justifica continuar o processo de secagem dos solos analisados.

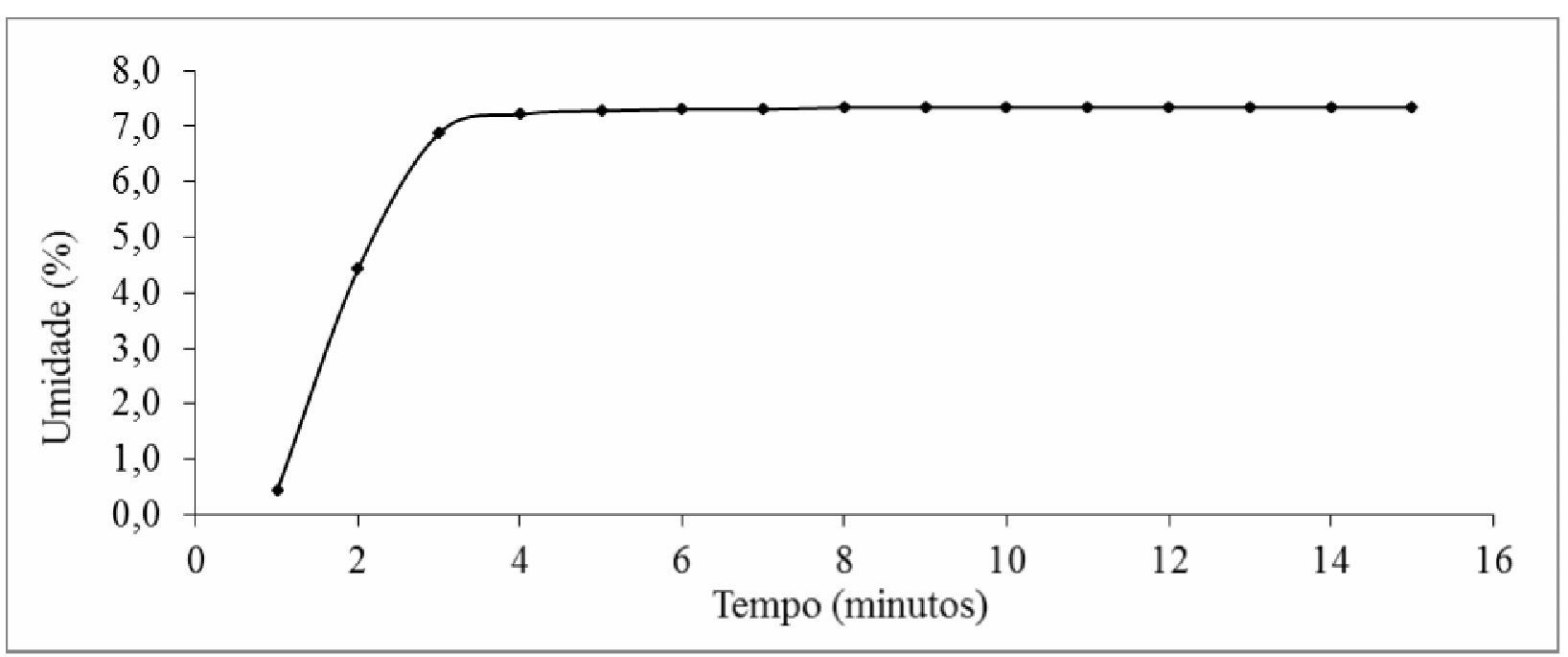

FIGURA 4 Curva de secagem da classe de solo Plintossolo Pétrico êutrico, profundidade de $0,20-0,40 \mathrm{~m}$ 


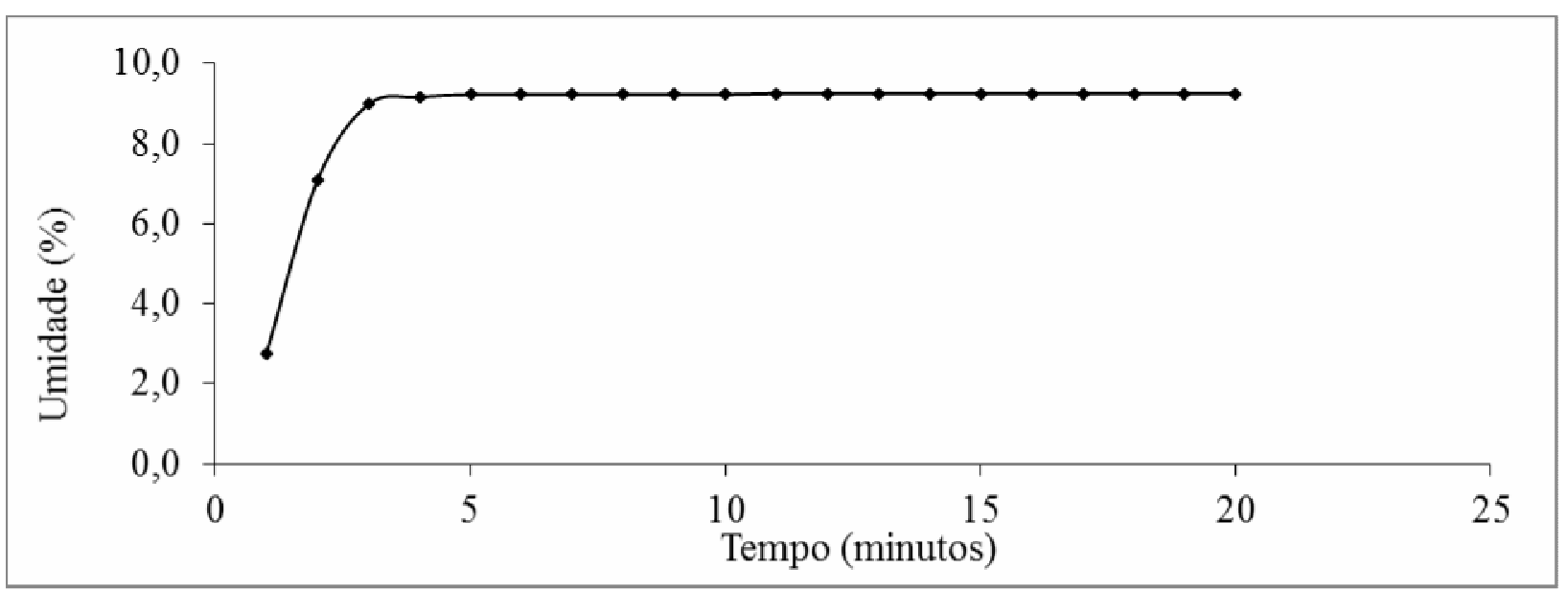

FIGURA 5 Curva de secagem da classe de solo Latossolo Amarelo, profundidade de $0,20-0,40 \mathrm{~m}$

De maneira geral, com exceção do Planassolo Nátrico, as curvas ajustadas são coincidentes para os tipos de solo de estudado, não necessitando de calibração para solos com características semelhantes. O infravermelho é uma ferramenta rápida para calibração de métodos indiretos. Embora o método de estufa seja o mais recomendado para a determinação de umidade e calibração de outros aparelhos, este apresenta a desvantagem de exigir maior tempo para a obtenção dos valores de umidade, em relação ao infravermelho e o forno micro-ondas. Há atraso de pelo menos 24 horas para a obtenção dos resultados em relação aos outros dois métodos.

É importante ressaltar que os resultados obtidos pelo método gravimétrico podem ser afetados pela pedregosidade e matéria orgânica presente na amostra. SANTOS et al. (2011) relataram que a umidade do solo apresentou elevada variabilidade no tempo, estando relacionada aos diferentes tipos de cobertura e propriedades do solo, a matéria orgânica mostrou ser a prática conservacionista mais adequada para manutenção da umidade do solo. É possível que a técnica indique diferenças na umidade do solo em cada ponto coletado, devido à heterogeneidade, portando não se deve comparar a umidade de solo de locais e profundidades diferentes (REYNOLDS, 1970). Sendo imprescindível, calibrar, tanto o método de estufa como os outros, para cada tipo e profundidade de solo antes da sua utilização. Todavia, diferentes métodos de determinação podem produzir resultados distintos, dependendo dos pressupostos assumidos (GHIBERTO \& MORAES, 2011).

\section{CONCLUSÕES}

O forno de micro-ondas doméstico e a balança de infravermelho apresentaram resultados semelhantes de umidade do solo. O micro-ondas torna alternativa viável para determinação de umidade de solo em condições não laboratoriais. 


\section{REFERÊNCIAS}

ARAÚJO, E. C. B.; AGUIAR, J. V.; COSTA, R. N. T. Calibração de um modelo de umidade para um solo aluvial sem cobertura vegetal. Revista Brasileira Engenharia Agrícola Ambiental, v. 5, p. 444-449, 2001.

ÁVILA, L. F.; MELLO, C. R.; MELLO, J. M.; SILVA, A. M. Padrão espaço-temporal da umidade volumétrica do solo em uma bacia hidrográfica com predominância de latossolos. Revista Brasileira de Ciência Solo, v. 35, p. 1801-1810, 2011.

BAIER, W.; ROBERTSON, G. W. The performance of soil moisture estimates as compared with the direct use of climatological data for estimating crop yields. Agricultural Meteorology, v. 5, p. 17-31, 1968.

CREMOM, C.; LONGO, L.; MAPELI, C. N.; SILVA, L. A. M.; SILVA, W. M. Determinação da umidade de diferentes solos do Pantanal Matogrossense via microondas e método padrão. Revista Agrarian, v. 7, n. 24, p. 280-288, 2014.

EMBRAPA - EMPRESA BRASILEIRA DE PESQUISA AGROPECUÁRIA. Manual de métodos de análises de solo. Centro Nacional de Levantamento e Conservação do Solo. Rio de Janeiro: Embrapa Solos. 1997. 212p

EMBRAPA - EMPRESA BRASILEIRA DE PESQUISA AGROPECUÁRIA. Centro Nacional de Pesquisa de Solos. Sistema brasileiro de classificação de solos. $2^{\mathrm{a}}$ Ed.; Rio de Janeiro: EMBRAPA, 2006. 306p.

FREITAS, W. A.; CARVALHO, J. A.; BRAGA, R. A.; ANDRADE, M. J. B. Manejo da irrigação utilizando sensor da umidade do solo alternativo. Revista Brasileira Engenharia Agrícola Ambiental, v. 16, n.3, p. 268-274, 2012.

GHIBERTO, P. J.; SERGIO OLIVEIRA MORAES, S. O. Comparação de métodos de determinação da condutividade hidráulica em um Latossolo vermelho-amarelo. Revista Brasileira Ciência do Solo, v. 35, p. 1177-1188, 2011.

GONÇALVES, A. C. A.; TRINTINALHA, M. A.; FOLEGATTI, M. V.; REZENDE, R.; TORMENA, C. A. Spatial variability and temporal stability of water storage in a cultivated tropical soil. Bragantia, v. 69, suplemento, p. 153-162, 2010.

MAZURANA, M.; LEVIEN R.; MÜLLER, J.; CONTE, O. Sistemas de preparo de solo: Alterações na estrutura do solo e rendimento das culturas. Revista Brasileira Ciência do Solo, v. 35, p. 1197-1206, 2011.

MIRANDA, E. P.; MARTINS, G. S.; CARMO, F. F.; LIMA, L. D. P.; SILVA, F. M. Uso do forno de microondas na determinação da umidade de um solo franco-siltoso. In: IV WINOTEC WORKSHOP INTERNACIONAL DE INOVAÇÕES TECNOLÓGICAS NA IRRIGAÇÃO. Fortaleza, 2012. Anais. Inovagri, p. 1-5.

ORTIGARA, C.; KOPPE, E.; LUZ, F. B.; BERTOLLO, A. M.; KAISER, D. R.; SILVA, V. R. Uso do solo e propriedades físico-mecânicas de Latossolo vermelho. Revista Brasileira Ciência do Solo, v. 38, p. 619-626, 2014. 
REYNOLDS, S. G. The gravimetric method of soil moisture determination. Parte I.A study of equipment, and methodological problems. Journal Hydrology, v.11, p. 258273, 1970.

SANTOS, T. E. M.; MONTENEGRO, A. A. A.; SILVA, D. D. Umidade do solo no semiárido pernambucano usando-se reflectometria no domínio do tempo (TDR). Revista Brasileira Engenharia Agrícola Ambiental, v. 15, n.7, p. 670-679, 2011.

SCARAMUZZA, J. F.; COUTO, G. E.; MARASCHIN, L. Física do solo: manual de aulas práticas. Cuiabá-MT, 2003. 59p.

SOUZA, G. B.; NOGUEIRA, A. C.; RASSINI, J. B. Determinação de matéria seca e umidade em solos e plantas com forno de microondas doméstico. Circular Técnica 33, EMBRAPA, 2002.

TAVARES, M. H. F.; CARDOSO, D. L.; GENTELINI, D. P.; GABRIEL FILHO, A.; EVANDRO KONOPATS, A. Uso do forno de microondas na determinação da umidade em diferentes tipos de solo. Semina: Ciências Agrárias, v. 29, p. 529-538, 2008.

TOMÉ, J. B.; DECHEN, A. R. Microwave oven-drying of soil samples for chemical testing in Brazil. Communications in soil science and plant analysis, v. 26, p. 515-529, 1995. 